\title{
Response to: Oral cancer of Sigmund Freud
}

\author{
Matteo Trimarchi ${ }^{1}$ (D) G. Bertazzoni ${ }^{2} \cdot$ M. Bussi $^{1}$
}

Received: 10 February 2019 / Accepted: 14 February 2019 / Published online: 19 March 2019

c) Springer-Verlag GmbH Germany, part of Springer Nature 2019

Historical accounts on Sigmund Freud's oral disease repeatedly report that histopathological examination of Freud's oral lesions was diagnostic for malignant neoplasm, as we have thoroughly recounted in our communication [1]. Indeed, a diagnosis of squamous cell carcinoma was formulated after Freud's first surgery in 1923 by the pathologist Jakob Erdheim [2], still known today for his contribution to the identification of Erdheim-Chester disease [3]. This diagnosis, as we have described, is conflicting with the long survival of the patient (16 years) [1]. Since Freud was a habitual cocaine user we hypothesized that his condition could be attributed to the necrotizing effect of cocaine abuse. Other authors have theorized that Freud actually suffered from verrucous squamous cell carcinoma [4], a clinico-pathological entity that was first recognized a few years after Freud's death [5]. Indeed, considering the historical accounts reviewed in both works, a diagnosis of verrucous squamous cell carcinoma can be reasonably taken into account. Historical evidences, particularly the long smoking history of the patient and the histopathological diagnosis of squamous cell carcinoma, make the diagnosis of verrucous carcinoma seem more plausible. However, we do not share the absolute confidence in this hypothesis shown by its advocates in their comment to our communication as we are, likewise, not unconditionally convinced about our theory. Indeed, both diagnoses have been proposed posthumously without having access to the histopathological specimens and solely based on historical accounts [1,4]. Available data do not provide conclusive evidence in favor of neither verrucous carcinoma nor cocaine-induced lesion $[1,4]$. It can be reasonably affirmed that in the absence of further

Matteo Trimarchi

trimarchi.matteo@hsr.it

1 Department of Otorhinolaryngology, San Raffaele Scientific Institute, Vita-Salute San Raffaele University, Via Olgettina 60, 20132 Milan, Italy

2 Department of Otorhinolaryngology, University of Brescia, Piazzale Spedali Civili 1, 25123 Brescia, Italy conclusive evidence, such as histopathological revision of surgical specimens, both theories deserve to be taken into consideration.

\section{Compliance with ethical standards}

Conflict of interest The authors declare no funding source and no conflict of interest.

\section{References}

1. Trimarchi M, Bertazzoni G, Bussi M (2019) The disease of Sigmund Freud: oral cancer or cocaine-induced lesion? Eur Arch Otorhinolaryngol 276:263-265

2. Davenport JC (1993) Sigmund Freud's illness - the ultimate team approach to head and neck cancer? Facial Plast Surg 9:125-132

3. Chester W (1930) Über Lipoidgranulomatose. Virchows Arch Pathol Anat 279:561-602

4. Teymoortash A, Silver CE, Rinaldo et al (2013) Verrucous carcinoma: a retrospective diagnosis in three historic patients. Eur Arch Otorhinolaryngol 271:631-633

5. Ackerman LV (1948) Verrucous carcinoma of the oral cavity. Surgery 23:670-678

Publisher's Note Springer Nature remains neutral with regard to jurisdictional claims in published maps and institutional affiliations. 